\title{
DO PARADOXO DA MÁGICA À INVESTIGAÇÃo DA CLÍNICA: PESQUISA, CLÍNICA E TERAPIA OCUPACIONAL
}

\author{
FROM THE MAGICAL PARADOX TO CLINICAL INVESTIGATION: RESEARCH, PRACTICE \\ AND OCCUPATIONAL THERAPY
}

\author{
DE LA PARADOJA DE LA MAGIA A LA INVESTIGACIÓN CLÍNICA: INVESTIGACIÓN, CLÍNICA \\ Y TERAPIA OCUPACIONAL
}

Recebido: 05/05/2014

Aprovado: 31/01/2015

Taís Quevedo Marcolino1

Este artigo tem como objetivo refletir sobre a trajetória clínica e de pesquisa, de uma profissional destacando a formação no Método Terapia Ocupacional Dinâmica. Para esse método, é na investigação do proceder em terapia ocupacional que se encontra o eixo central para a produção de conhecimentos sobre a prática, buscando por generalizações e teorias que sustentem essa prática, desmistificar o que parece mágica, incompreensível e difícil de ser transmitido. Neste ensaio, são apresentados delineamentos de pesquisas nessa direção. No cenário atual, de crescimento da produção científica, espera-se apresentar questionamentos valorizando aspectos da investigação da prática em terapia ocupacional no Brasil, que estimulem o debate acerca da pesquisa e da clínica, em um diálogo que dê à clínica e à prática profissional, um lugar de destaque para as produções acadêmicas e científicas.

Descritores: Terapia Ocupacional; Pesquisa; Conhecimentos, atitudes e prática em saúde.

This article aimed discusses the about clinical and research trajectory of a professional, highlighting the training method in Dynamic Occupational Therapy Method. For this method, the investigation of occupational therapy practice in the central axis is for the production of practical knowledge, searching for generalizations and theories that support this practice, to demystify what is seems to be magical, incomprehensible and difficult to be transmitted. In this essay presents outlines of research in this direction. In the present scenario of growing of scientific production, is expected to submit questions valuing aspects of research practice in occupational therapy in Brazil, to stimulate debate about research and clinical care, in a dialogue that gives tot clinical professional practice a prominent place for the academic and scientific productions.

Descriptors: Occupational Therapy; Research; Health knowledge, attitudes, practice.

Este artículo tiene como objetivo reflexionar sobre la trayectoria clínica y de investigación, de una profesional, destacando el entrenamiento en el Método Terapia Ocupacional Dinámica. Para este método, el proceder en la terapia ocupacional es el eje central es para la producción de conocimientos sobre la práctica, la búsqueda de generalizaciones y teorías que apoyan esta práctica, desmitificar lo que parece mágico, incomprensible y difícil de transmitir. En este ensayo, diseños de investigación se presentan en esta dirección. En el escenario actual, de crecimiento de la producción científica, se espera presentar preguntas valorando los aspectos de la investigación de la práctica en terapia ocupacional en el Brasil, que estimulen el debate a cerca de la investigación y la clínica, en un diálogo en él cuál la clínica y la práctica profesional, tenga un lugar destacado para las producciones académicas y científicas.

Descriptores: Terapia Ocupacional; Investigación; Conocimientos, actitudes y práctica en salud.

1Terapeuta Ocupacional. Especialista no Método Terapia Ocupacional Dinâmica. Mestre e Doutora em Educação. Professora Adjunta do Departamento de Terapia Ocupacional da Universidade Federal de São Carlos. taisquevedo@gmail.com 


\section{INTRODUÇÃO}

$D$ ara discutir o tema Pesquisa, Clínica e Terapia Ocupacional, em uma perspectiva qualitativa, parte-se do pressuposto de que o pesquisador é quem garante a credibilidade nas pesquisas qualitativas, a partir da sua formação e das atitudes que toma ao longo do trabalho de investigação $0^{1,2}$.

Assim, ao apresentar uma trajetória profissional, destaca-se o quanto a formação no Método Terapia Ocupacional Dinâmica (MTOD), pelo Centro de Especialidades Terapia Ocupacional (CETO) foi um ponto de mutação na prática clínica a ser apresentada e uma marca para a formação em pesquisa.

O MTOD foi construído em um processo de teoria da técnica, para o qual "a partir da observação e análise dos fenômenos clínicos, se constrói generalizações que possam oferecer explicações de ordem teórica e que sustentem um arcabouço teóricometodológico que se volte novamente para a clínica"3(p. 647). Assim, ofereceu ferramentas que ensinaram a transitar na relação triádica (terapeuta, sujeito-alvo e atividades), a partir da singularidade de cada sujeito e a compreender que é na investigação deste proceder em terapia ocupacional que se encontra o eixo central para a produção de conhecimentos na área.

Desde o início até as produções mais recentes do CETO ressalta-se a necessidade de ampliar ao máximo as compreensões sobre este 'saber fazer acerca de', a investigação da intervenção clínica de forma metódica para que, como consequência, haja possibilidades de viabilização de construções teóricas ${ }^{4,5}$.

Assim, demarca a atitude científica, como disposição emocional e organização intelectual para ir ao encontro da compreensão dos fenômenos da natureza e do ser humano, ${ }^{6}$ necessária para que o pesquisador-profissional/clínico possa trilhar um caminho de analisar tanto seus resultados, ainda que singulares em cada caso, como os processos que levaram a esses resultados, identificando o que pode ser aceito como explicação e generalizado para outras situações da prática clínica.
Outro caminho necessário, entretanto, reside na atividade científica, que se desenvolve sob normas específicas, a partir de aportes teóricos e metodológicos, também com o objetivo explícito de ampliar a generalização das coisas da natureza e do homem. Desse modo, diversas perguntas podem ser feitas para se compreender os fenômenos e, dependendo do que se quer conhecer, do tipo de pergunta a ser feita, é que será organizado o delineamento metodológico para a investigação.

No que se refere ao estudo da clínica, tendo como foco a investigação no proceder em terapia ocupacional para produzir conhecimentos, na direção de desvelar elementos que possam ser generalizados e, posteriormente, transmitidos - Quais são as perguntas que devem ser feitas e quais metodologias virão ao nosso encontro?

Assim, este artigo tem como objetivo refletir sobre a trajetória clínica e de pesquisa, de uma profissional destacando a formação no Método Terapia Ocupacional Dinâmica.

\section{MÉTODO}

Este artigo se fundamenta na perspectiva de uma reflexão sobre a Terapia Ocupacional associando conhecimentos, prática profissional e reflexões com a literatura pertinente.

\section{TERAPIA OCUPACIONAL, CLÍNICA E PESQUISA}

Propõe-se começar com um questionamento sobre a importância da pesquisa a partir da prática:

“... em primeiro lugar, que mais importante que definir uma profissão ou disciplina como ciência é inventar práticas que possam ser colocadas em julgamento por terceiros e isto é, sem dúvida, da ordem do estudioso e não da matéria estudada. Em segundo lugar, uma pergunta: como as terapeutas ocupacionais estudam suas práticas?"7 (p. 06)

Colocar a prática como eixo central da produção de conhecimentos significa se afastar de concepções para as quais a prática é o resultado da aplicação de teorias, e que na Terapia Ocupacional muitas vezes se traduz 
por teorias oriundas de outros campos de conhecimento.

"Inventar práticas" não é um termo estranho para terapeutas ocupacionais acostumados a trabalhar com populações em situações de exclusão pessoal e social. Mas colocá-las para o julgamento de terceiros, para validá-las ou não, torná-las conhecidas e valorizadas pela comunidade da Terapia Ocupacional ou abandoná-las, não é algo a que se esteja acostumado.

É possível questionar a atitude científica das (os) terapeutas ocupacionais em seu cotidiano, mas é na atividade científica que se pode ter um julgamento mais próximo das necessidades do campo. Entretanto, essa atividade científica não pode se afastar das (os) terapeutas ocupacionais e ainda deverá incitar a atitude científica necessária para que sejam colaboradores em projetos de investigação da prática.

No final da década de 1980, a Associação Americana de Terapia Ocupacional e a Fundação Americana de Terapia Ocupacional (AOTA/AOTF) encomendaram uma grande pesquisa sobre o que era possível apreender da prática em Terapia Ocupacional a partir dos conteúdos e dos processos de raciocínio clínico dos profissionais. A partir desta pergunta, todo o delineamento metodológico da pesquisa foi centrado nas significações que os terapeutas ocupacionais ofereciam às suas ações ${ }^{8}$. Os profissionais precisaram se tornar investigadores da sua própria prática e se arriscar a explicitar suas compreensões para colegas, seja eles pares ou pesquisadores, com a intenção de descobrir o que estava implícito, questioná-lo e modificar compreensões e práticas. Este foi um caminho de duas vias, pois operou tanto na direção de uma melhoria da prática para os profissionais como, para os fins da pesquisa. 0 que se tornou explícito pode ser sistematizado para uma discussão teórica sobre como acontece a prática em Terapia Ocupacional.

Esta é uma possível resposta sobre como terapeutas ocupacionais estão investigando suas práticas. Esta pesquisa abriu novas possibilidades para a Terapia
Ocupacional no cenário internacional e muitas outras publicações surgiram a partir dela $^{9-14}$.

Nessa reflexão, entretanto, destaca-se o que é colocado como necessidade de pesquisa nesse campo: investigar tanto quais referenciais teóricos são utilizados por terapeuta ocupacionais em seu processo de construção do problema e tomada de decisões sobre como agir na prática, bem como, quais referenciais teóricos (modelos e métodos) propostos em Terapia Ocupacional influenciam o raciocínio clínico ${ }^{9}$.

Este tipo de pesquisa sobre como a prática acontece ainda é incipiente. Os livros de fundamentos de Terapia Ocupacional oferecem uma gama de modelos e quadros teóricos, mas raras são as pesquisas que procuram compreender de que modo estes referenciais estão presentes na prática.

Um exemplo disso pode ser encontrado em uma pesquisa realizada para compreender como o conceito de volição do Modelo da Ocupação Humana se fez presente tanto para a compreensão da motivação diante de uma doença crônica como no processo terapêutico em terapia ocupacional. Essa investigação evidenciou um resultado secundário desfavorável, pois a terapeuta ocupacional que dizia trabalhar sob os pressupostos do Modelo da Ocupação Humana apresentou uma compreensão sobre a volição dos pacientes bastante diferente das deles, e os autores precisaram pontuar a falta de compreensão deste conceito por parte da profissional ${ }^{15}$.

Assim, várias perguntas podem ser disparadas - Será que é só para essa profissional? Até que ponto as classificações dos referenciais teóricos são condizentes com a prática? Como e quais conceitos e ideias teóricas são incorporados pelo profissional em sua prática? Em que contexto? Como compreender os modelos positivista, humanista e materialistahistórico, ainda estudado na formação inicial, bem como, sua real significação para os profissionais? Mais ainda - De que teorias se precisam? Com o que efetivamente se esta contando para as decisões clínicas? 
Além disso, as pesquisas sobre raciocínio clínico têm apresentado resultados mais referentes à sua forma - que tipo de raciocínio está em ação - do que questionado, avaliado e validado nas práticas desempenhadas por terapeutas ocupacionais e os conteúdos desses pensamentos no sentido de compreender quais referenciais estão em jogo ${ }^{9}$.

Diante dessas questões, na experiência profissional aqui citada, tem se buscado construir uma investigação mais sistemática da clínica, que valorize os modos de proceder de terapeutas ocupacionais. $\mathrm{Na}$ dissertação de mestrado da autora procurou-se compreender como a dimensão pedagógica se fazia presente nos pensamentos e procedimentos de uma terapeuta ocupacional ${ }^{16}$. Em uma revisão bibliográfica, terapeutas ocupacionais que valorizavam a dimensão educativa presente na prática, muitas vezes, ressaltavam a importância de se ter abordagens educacionais coerentes com modelos de práticas na terapia ocupacional. Então, uma terapeuta ocupacional que trabalhe sob um referencial psicanalítico não poderia utilizar uma abordagem educacional comportamental, pois sua prática não atingiria os resultados esperados ${ }^{16}$.

Novamente, deparou-se com trabalhos que colocavam os referenciais teóricos acima da prática e pouco analisavam como eram construídas as ações educativas nos processos terapêuticos em terapia ocupacional.

Como o foco do trabalho era a compreensão das ações educativas a partir do referencial do MTOD, foram incluídos, nessa revisão, trabalhos publicados na Revista CETO. Para o MTOD todos os procedimentos da (o) terapeuta ocupacional tem que estar voltados para as singularidades do sujeito-alvo, e há uma composição entre a ação educativa e função terapêutica. Isto pareceu diferente de escolher um referencial teórico à priori, pois o foco estava no que era importante para o sujeito-alvo.

“... É no processo de ensinar e aprender atividades na terapia ocupacional que a singularidade de um cotidiano começa a ser construída: descobertas de novas capacidades e habilidades, de novos gostos ou mesmo de gostos antigos, de projetos que se originam numa integração do indivíduo com ele mesmo e que demandam sua integração com outros indivíduos, para o social"16 (p. 44-45).

Assim, com a pergunta: "O que é possível apreender, a partir do processo de reflexão sobre a ação explicitado nas narrativas de uma terapeuta ocupacional, acerca da dimensão pedagógica nos procedimentos de terapia ocupacional?", foi possível delinear a metodologia de pesquisa na qual uma terapeuta ocupacional experiente, que trabalhava com o MTOD, produziu narrativas escritas sobre dez atendimentos sequenciais com uma paciente adolescente, portadora de esquizofrenia, nas quais ela descreveu os acontecimentos das sessões, bem como suas reflexões sobre eles.

Depois de uma análise sobre os diferentes tipos de reflexão da terapeuta ocupacional foi possível identificar que a dimensão pedagógica esteve presente durante o processo diagnóstico e também quando ela descrevia ações e reflexões na direção de procurar compreender o modo como a paciente aprendia, centrada tanto no aqui-e-agora da sessão como em momentos anteriores e nas informações do cotidiano. Além disso, as reflexões abarcaram as consequências das suas ações, tanto a partir destas compreensões como a partir das hipóteses para a condução do processo terapêutico. Deste modo, tornou-se possível encontrar coerência entre os pressupostos do MTOD e a prática da terapeuta ocupacional, no que se refere à centralidade da ação educativa na condução do processo terapêutico.

Na pesquisa de doutorado ${ }^{17}$ da mesma profissional, cujo objetivo foi $\mathrm{o}$ de compreender processos de raciocínio clínico e desenvolvimento profissional em terapeutas ocupacionais em início de carreira, o trabalho de campo foi realizado junto a um grupo de seis profissionais em início de carreira e duas terapeutas ocupacionais experientes, colaboradoras do 
projeto. 0 processo, assim como na pesquisa de raciocínio clínico da AOTA/AOTF, foi o de transformá-las em investigadoras da própria prática de modo a produzir sentidos sobre ela e desvelar aspectos implícitos ${ }^{18}$. Em certo encontro do grupo, quando se discutia o como validar o trabalho da (o) terapeuta ocupacional, ou ainda, como explicar a terapia ocupacional de modo que seja compreendida, uma das participantes relata o discurso de encantamento de seus colegas não-terapeutas ocupacionais diante de seu trabalho, como que validando o resultado, mas recorrendo à mágica para compreendêlo.

"Eu acho que tem todas essas particularidades, [...] que não é o que é tido como o tradicional, o científico, o que é valido, dá o resultado que talvez a sociedade espere, [...] alguém fala 'nossa, a maleta mágica' [maleta de materiais], [...] parece que você abre a maleta, encanta todo mundo, porque eu acho que também tem a dificuldade de entender como a coisa acontece, [...] tem muito a ver com uma relação, [...] por outro lado eu acho que a gente também vai entrando, [...] num lugar que dá muito medo de dizer que não é isso, porque se não for isso, [...], e agora, né?'”'

"Que é o paradoxo da mágica, [...] o que é mágico é uma ilusão, não é, mas tipo faz parecer que é, é algo que você não entende o que tá por traz, mas que, [...] produz um resultado [...]"

Um resultado dessa pesquisa foi a de desvelar que um dos maiores dilemas dos terapeutas ocupacionais em início de carreira - e que se arrisca refletir se não se constitui como um dilema da profissão - é colocar em palavras próprias e públicas, que não as emprestadas do saber biomédico ou psicológico, os porquês de seus procedimentos e dos processos envolvidos nos casos de sucesso ou fracasso ${ }^{19}$.

Nesta direção, a produção de conhecimentos a partir da prática não deveria se restringir ao pragmatismo uma vez que pode/deve buscar por generalizações e teorias que sustentem essa prática. Nesse sentido, assumem um lugar como o da ciência, no sentido de desmistificar o que é mágico, incompreensível e difícil de ser transmitido.

A complexidade da prática na Terapia Ocupacional, mesmo com toda a magia e a poesia inerentes a ela - como pode ser visto na descrição da antropóloga que, ao nos observar constata que "Havia mais generosidade do que eu fora preparada. Eu vi pequenas ternuras ao invés de intervenções [...]"19 (p. 22, tradução nossa) que "Eu não podia desconsiderar estas mulheres, ou a feminilidade de suas preocupações com os detalhes da vida cotidiana [...] Há uma certa fluidez nesta prática, do ridículo ao sublime, do trivial ao essencial [...]"19 (p. 51, tradução nossa) demanda ser posta como objeto de estudo em investigações acadêmicas e científicas que a torne inteligível e passível de generalizações.

Este modo de produzir conhecimento se sustenta nas construções sobre as ciências modernas de que a incerteza é a marca das ciências de campo, e que para compreender o objeto é o sujeito quem precisa inventar modos de investigar capazes de reunir indícios e identificar relações que tornem o objeto inteligível ${ }^{7,20}$.

A terapia ocupacional (prática), posta como objeto de estudo, implica o terapeuta ocupacional (estudioso) na invenção de práticas de investigação que ofereçam possibilidades (abertas ao risco) de apreensão/compreensão "das condições humanas de intervenções, na ocorrência de uma terapia ocupacional" 7 (p.6) dos fenômenos relativos ao saber fazer acerca da terapia ocupacional.

\section{CONCLUSÃO}

Com essas reflexões, espera-se demarcar de que, o conhecimento produzido nesse tipo de investigação tem que ser relevante para a prática.

0 que diferencia esta inteligibilidade (produzir conhecimentos a partir da incerteza e de novos modos de inventar a prática) de uma opinião qualquer e não a deixa vulnerável a qualquer opinião embora crie espaço para a vulnerabilidade é a possibilidade de pôr à prova de terceiros este modo de investigar. 
A terapia ocupacional é 'feita existir' pelo terapeuta ocupacional que investiga, e este modo de conhecer é diferente daquele que pretende provar uma existência.

Esta proposta de produção de conhecimento demanda uma prática de pesquisa para apreender e compreender outra prática, a de cuidado. Esta experiência de cuidar é produzida por terapeutas ocupacionais, o que os torna indissociáveis de qualquer investigação.

No cenário atual, de crescimento da produção científica na Terapia Ocupacional no Brasil, espera-se, com este ensaio, apresentar questões que valorizem aspectos da investigação da prática em terapia ocupacional e estimular o debate acerca da pesquisa e da clínica, em um diálogo que dê à clínica e à prática profissional, um lugar de destaque para as produções acadêmicas e científicas.

\section{REFERÊNCIAS}

1. Geertz C. O pensamento como ato moral: dimensões éticas do trabalho de campo antropológico em países novos. Rio de Janeiro: Jorge Zahar; 2001.

2. Patton MQ. Qualitative research and evaluation methods: integrating theory and practice. California: Sage Publications; 2014.

3. Benetton MJ, Marcolino TQ. As atividades no método terapia ocupacional dinâmica. Cad Ter Ocup UFSCar. 2013; 21(3):645-53.

4. Benetton MJ. O encontro do sentido do cotidiano na terapia ocupacional para a construção de significados. Rev CETO. 2010; (12):32-9.

5. Benetton, MJ. A narrativa clínica no método terapia ocupacional dinâmica. Rev CETO. 2012; (13):4-8.

6. Turato ER. Tratado da metodologia da pesquisa clínico-qualitativa. Petrópolis: Vozes; 2003.

7. Benetton MJ. Além da opinião: uma questão de investigação para a historização da terapia ocupacional. Rev CETO. 2005; (9):4-8.

8. Mattingly C, Gillette N. Antropology occupational therapy and action research. Am J Occup Ther. 1991; 45(11):972-8.

9. Robertson L. Clinical reasoning in occupational therapy: controversies in practice. West Sussex, UK: Wiley-Blackell; 2012.

10. Towns E, Ashby S. The influence of practice educators on occupational therapy students' understanding of the practical applications of theoretical knowledge: a phenomenological study into student experiences of practice education. Aust Occup Ther J. 2014; 61(5):344-52.

11. Carrier A, Levasseur M, Bédard D, Desrosiers J. Community occupational therapists' clinical reasoning: identifying tacit knowledge. Aust Occup Ther J. 2010; 57(6):356-65.

12. Scanlan JN, Hancock N. Online discussions develop students' clinical reasoning skills during fieldwork. Aust Occup Ther J. 2010; 57(6):401-8.

13. Carrier A, Levasseur M, Bédard, D, Desrosiers J. Clinical reasoning process underlying choice of teaching strategies: a framework to improve occupational therapists' transfer skill interventions. Aust Occup Ther J. 2012; 59(5):355-66.

14. Shafaroodi N, Kamali M, Parvizy S, Mehraban AH, O'Toole G. Factors affecting clinical reasoning of occupational therapists: a qualitative study. Med J Islam Repub Iran. 2014; 28:8.

15. Helfrich C, Kielhofner G, Mattingly C. Volition as narrative understanding motivation in chronic illness. Am J Occup Ther. 1994; 48(4):311-7.

16. Marcolino TQ. A dimensão pedagógica nos procedimentos de terapia ocupacional Dissertação [mestrado]. São Carlos: Universidade Federal de São Carlos; 2005.

17. Marcolino TQ. A porta está aberta: aprendizagem colaborativa, prática iniciante, raciocínio clínico e terapia ocupacional. Tese [doutorado]. São Carlos: Universidade Federal de São Carlos; 2009.

18. Schön D. The reflexive practioner. New York: Basic books; 1983.

19. Mattingly C. Healing dramas and clinical plots: the narrative structure of experience. Cambridge: Cambridge University Press; 1998.

20. Stengers I. A invenção das ciências modernas. São Paulo: Editora 34; 2002.

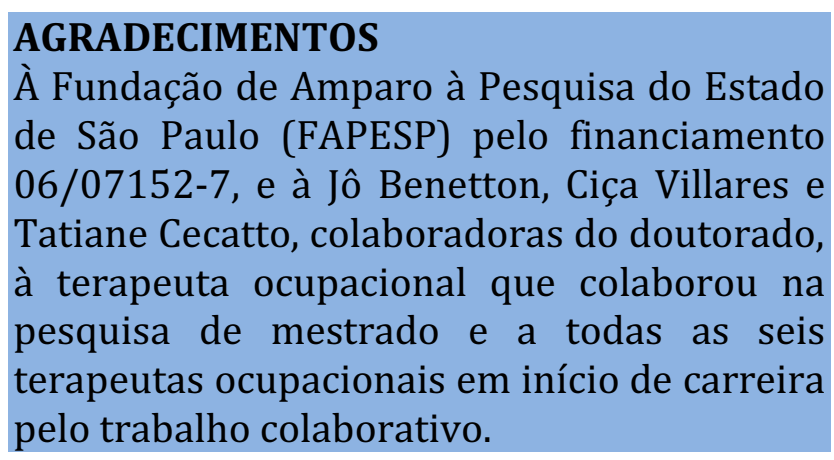

\section{CONTRIBUIÇÕES}

Taís Quevedo Marcolino foi responsável pela construção e redação do artigo. 